\title{
The Association of Uncarboxylated Matrix Gla Protein with Mitral Annular Calcification in Patients without Significant Coronary Artery Disease
}

\author{
Zeki Simsek, Elnur Alizade', Firdovsi Ibrahimov'², Ali Metin Esen ${ }^{3}$ \\ Department of Cardiology, Tuzla State Hospital, 'Department of Cardiology, Kartal Kosuyolu Heart Research and Training Hospital, ${ }^{3}$ Department of Cardiology, \\ Memorial Clinic Hospital, Istanbul, Turkey, ${ }^{2}$ Department of Cardiology, Central Clinic Hospital, Baku, Azerbaijan
}

\section{Abstract}

Objective: Mitral annular calcification (MAC) is associated with systemic calcification and cardiovascular disease (CVD) events. Matrix Gla protein (MGP) is a strong inhibitor of vascular and soft-tissue calcification and reduced levels of its circulating precursor, uncarboxylated MGP (ucMGP), was found associated with vascular calcification in pilot studies. Methods and Results: In this study, which includes 86 outpatients with no significant coronary artery and chronic kidney diseases, we measured serum ucMGP levels and evaluated MAC using echocardiography. In participants with MAC $(n=44)$, serum ucMGP levels were lower than the control group $(n=42)(216.1 \pm 154.1$ vs. $390.2 \pm 256.3, P=0.001$, respectively). The patients with MAC were divided into two groups: mild MAC group and moderate MAC group. Serum ucMGP levels were significantly lower in the moderate MAC group than the mild MAC group (139.0 \pm 121.8 vs. $248.4 \pm 156.3$, $P=0.03$, respectively). Conclusions: In patients with MAC, serum ucMGP level was significantly low, and this association has been detected for the first time in patients with no significant coronary artery disease (CAD).

Keywords: Matrix gla protein, mitral annular calcification, uncarboxylated matrix Gla protein

\section{INTRODUCTION}

Mitral annular calcification (MAC) is a chronic, degenerative, and noninflammatory disease of the mitral valve. ${ }^{[1,2]}$ The prevalence of MAC increases with age, and MAC most frequently occurs in postmenopausal women. ${ }^{[3-5]}$ Diagnosis is made on observing the increase in opacity in the mitral valve annulus using transthoracic echocardiography (TTE). MAC may result in mitral stenosis, mitral regurgitation, infective endocarditis, atrial arrhythmias, and heart block. It is one of the known independent risk factors for systemic embolism and stroke. MAC severity as measured by the thickness of the valve in $\mathrm{M}$ mode is linearly correlated with the risk of stroke. ${ }^{[6,7]}$ Along with other calcific valvular processes, MAC is associated with a high prevalence of risk factors for the development of coronary atherosclerosis ${ }^{[8]}$ Framingham trial, which studied the correlation between MAC and cardiovascular mortality and morbidity, established that there is a relationship between MAC and cardiovascular event, cardiovascular death, and all-cause mortality. ${ }^{[9]}$

\begin{tabular}{|l|l|}
\hline \multicolumn{2}{|c|}{ Access this article online } \\
\hline Quick Response Code: & Website: \\
\hline & http:/www.ijcva.com \\
\cline { 2 - 2 } & \\
\hline
\end{tabular}

Matrix Gla protein (MGP) is an extracellular matrix protein whose synthesis depends on Vitamin $\mathrm{K}$, and it inhibits vascular calcification by binding to calcium ions. The primary sites of synthesis of this most important protein that regulates vascular calcium metabolism are cartilage, lung, heart, kidney, vascular smooth muscle cells, and calcific atherosclerotic plaque. ${ }^{[10,11]}$ MGP knock-out mice are characterized by severe vascular calcification and die prematurely due to spontaneous aortic rupture. ${ }^{[12]}$ In a pilot study, it was found that individuals with coronary atherosclerosis, aortic stenosis, and calcific uremic arteriolopathy had lower ucMPG levels compared to healthy controls. ${ }^{[13]}$ A previously published study determined the correlation between MAC and serum uncarboxylated

Address for correspondence: Dr. Elnur Alizade, Department of Cardiology, Tuzla State Hospital, Denizer Street, 34846 Istanbul, Turkey. E-mail: elnur17@hotmail.com

This is an open access journal, and articles are distributed under the terms of the Creative Commons Attribution-NonCommercial-ShareAlike 4.0 License, which allows others to remix, tweak, and build upon the work non-commercially, as long as appropriate credit is given and the new creations are licensed under the identical terms.

For reprints contact: reprints@medknow.com

How to cite this article: Simsek Z, Alizade E, Ibrahimov F, Esen AM. The association of uncarboxylated matrix Gla protein with mitral annular calcification in patients without significant coronary artery disease. Int $\mathrm{J}$ Cardiovasc Acad 2018;4:19-22. 
MGP (ucMGP) levels in patients with cardiovascular disease (CVD). ${ }^{[14]}$ The objective of the present study is to determine the independent association of serum ucMGP with MAC in outpatients with no significant CVD.

\section{Study Design and Methods}

\section{Study participants}

Between 2008 and 2009, we recruited 44 patients with MAC detected by TTE. Forty-two age and gender-match, healthy volunteers with no medical comorbidities, and receiving no cardioactive medications included in the study. Patients with rheumatic heart disease, severe/significant coronary artery disease (CAD), chronic renal failure, hypertrophic cardiomyopathy, cardiac failure, severe valvular disease, and patients under statin therapy were excluded from the study. Severe CAD patients were excluded myocardial perfusion scintigraphy both MAC and control groups. We performed invasive coronary angiography both mild and moderate coronary artery patients, which detected by myocardial perfusion scintigraphy, and significant $(>70 \%$ stenosis in a major coronary vessel) CAD patients were excluded from the study. Before data collection, written informed consent was obtained from each patient, and the study had been approved by the appropriate Institutional Ethics Review Committee.

All transthoracic echocardiographic examinations were performed using GE Vingmed system 5 (Horten, Norway), accompanied by electrocardiogram monitoring. Echocardiographic examination was performed in the left lateral decubitus position, in accordance with the relevant guidelines. Parasternal long and short axes, apical four chamber, apical two-chamber, and apical three-chamber windows of all patients were visualized using two-dimensional echo and color Doppler. Left ventricular end diastolic diameter (LVEDD), left ventricular end systolic diameter (LVESD), left atrial diameter, left ventricular, septal and posterior wall thickness, mitral flow velocity pulse, and continuous wave Doppler were analyzed. The studies were recorded digitally. After saving the echocardiographic data, blood samples were obtained from patients and these samples were collected in biochemistry tubes with citrate. Samples were incubated for $15 \mathrm{~min}$ at room temperature. Blood samples were centrifuged at $3000 \mathrm{rpm}$ for $15 \mathrm{~min}$; serum was separated from the plasma and stored at $-80^{\circ} \mathrm{C}$ for the future analysis.

\section{Measurements}

\section{Uncarboxylated matrix Gla protein}

Serum ucMGP was measured by competitive enzyme-linked immunosorbent assay using VitaK BV (Maastricht, the Netherlands) as previously described. ${ }^{[13]}$ Anti-ucMGP (VitaK BV, Maastricht, The Netherlands) was conjugated to the microtiter plate through polyclonal rabbit-antimouse IgG (Dako, Heverlee, Belgium). After stringent washing, $5 \mathrm{~mL}$ of the serum sample or standard was mixed with tracer (biotinylated peptide consisting of residues 35-54 in human MGP), transferred to the microtiter plate, and incubated overnight at $4^{\circ} \mathrm{C}$. After washing, the plate was incubated with streptavidin-peroxidase (Zymed, Breda, The Netherlands) and stained with TMB Microwell Proxidase Substrate Kit (KPL, Gennep, The Netherlands). The process was terminated by adding $\mathrm{H}_{2} \mathrm{SO}_{4}$, and the plate was read at $450 \mathrm{~nm}$. The lower limit of detection was $98 \mathrm{nM}$, and the intra-assay coefficient of variation was $6 \%$ and the interassay coefficient was $11 \%$.

\section{Mitral annular calcification}

Using GE Vingmed system 5 (Horten, Norway) echocardiograms were obtained at rest with all standard two-dimensional views and Doppler images. MAC is defined as an echo-dense structure located at the junction of the atrioventricular groove and the posterior mitral leaflet on the parasternal long-axis, apical 4-chamber, or parasternal short-axis view. MAC was divided into three groups according to the degree of calcification; mild, moderate, and severe.

Mild - Focal echodensity increase in mitral annulus.

Moderate - Echodensity increase is $<1 / 2$ and more than $1 / 3$ of the mitral annulus.

Severe - Calcification more than $1 / 2$ of the mitral annulus or calcification coating left ventricular outflow tract.

\section{Other associated characteristics}

Age, sex, race/ethnicity, smoking status, medical history of hypertension, diabetes, chronic kidney disease, myocardial infarction, angioplasty, coronary bypass, and heart failure were all determined by the answers to the patient questionnaire. Laboratory measures were made using standard clinical chemistry analyzers.

\section{Statistical analysis}

The statistical analyses were carried out using the SPSS 15.0 software (SPSS Inc., Chicago, IL, USA). Parametric variables were expressed as mean \pm standard deviation; while the categorical variables were expressed in percentage. Continuous variables outside the normal distribution were analyzed using the Mann-Whitney U-test, while those within the normal distribution were analyzed through Student's $t$-test. The one-way analysis of variance test was used to compare the categorical variables analyses. $P<0.05$ was considered statistically significant.

\section{RESULTS}

Both groups were similar regarding their demographic characteristics. Hypertension prevalence was significantly higher in the group with MAC (54.5\% and 33.3, $P=0.048)$. Each of the two groups had no significant differences regarding the frequency of diabetes mellitus and dyslipidemia. Left ventricular hypertrophy was observed significantly more commonly in the group with MAC (52.3 and 8.23, $P=0.006)$. Left atrial diameter was significantly larger in the group with MAC (3.3 vs. 3.1, $P=0.011)$. There were no significant differences between the two groups regarding LVEDD and LVESD [Table 1]. Serum MGP levels were significantly lower in the MAC group 


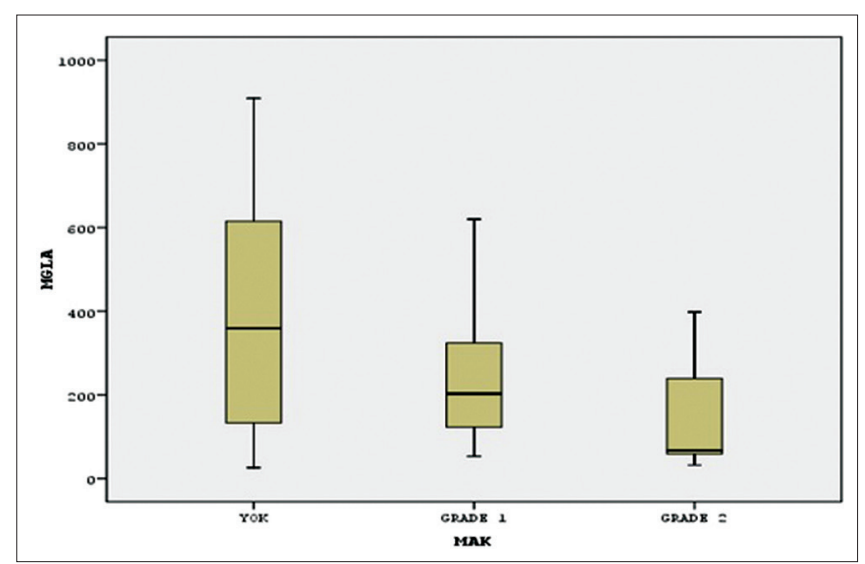

Figure 1: Serum MGP levels and the relationship between the degree of MAC

$(216.1 \pm 154.1$ vs. $390.2 \pm 256.3, P=0.001$, respectively) [Table 2]. The relationship between serum MGP and MAC grade was evaluated, and it was found that there was an increase in the degree of MAC-associated reduction of serum MGP levels [Figure 1].

\section{Discussion}

A previously conducted study using the same ucMGP assay demonstrated an association between lower ucMGP in people with CVD. Our study demonstrated that serum ucMGP levels were significantly lower in patients with MAC, and ucMGP levels were significantly lower even in the moderate MAC group compared to the mild MAC group. This association is detected for the first time in patients without significant CAD. A similar association was observed between ucMGP and MAC but was limited to participants with CAD. We performed myocardial perfusion scintigraphy in both MAC and control groups to exclude severe CAD. The statistical difference between mild and moderate MAC group regarding serum ucMGP levels strongly corroborated the correlation between serum ucMGP levels and dystrophic calcification.

Previous epidemiological studies evaluating the associations of ucMGP with dystrophic calcification have largely been limited to populations with end-stage renal disease and CAD, in which lower ucMGP concentrations are associated with vascular and valvular calcification and mortality. ${ }^{[15-19]}$ Here, we demonstrate an inverse association of ucMGP with dystrophic valvular calcification in a population without severe kidney disease and CAD. Together, these data suggest that ucMGP may function as an inhibitor of dystrophic calcification in other populations and is not limited to persons with end-stage renal disease and severe CAD.

\section{ConcLusion}

In summary, ucMGLA protein concentrations are inversely associated with MAC in people without CAD and severe kidney disease. In the context of previous studies, these data corroborate the hypothesis that MGP may function as an

\begin{tabular}{lccc}
\hline $\begin{array}{l}\text { Table 1: Groups of patient's demographic, clinical, and } \\
\text { echocardiographic characteristics }\end{array}$ \\
$\begin{array}{lccc}\text { Group 1 (MAC), } \\
\boldsymbol{n} \text { (\%) (mean) }\end{array}$ & $\begin{array}{c}\text { Group 2 (control), } \\
\boldsymbol{n} \text { (\%) (mean) }\end{array}$ & $\boldsymbol{P}$ \\
\hline Age (year) & 70.54 & 70.25 & 0.855 \\
Sex & & & \\
Female & $36(81.8)$ & $34(81)$ & \\
Male & $8(18.2)$ & $8(19)$ & \\
Hypertension & $24(54.5)$ & $14(33.3)$ & 0.048 \\
Diabetes mellitus & $13(29.5)$ & $10(23.8)$ & 0.803 \\
Dyslipidemia & $13(29.5)$ & $14(33.3)$ & 0.709 \\
LVH & $23(52.3)$ & $10(23.8)$ & 0.006 \\
LA (cm) & 3.3 & 3.1 & 0.011 \\
LVEDD & 4.8 & 4.78 & 0.689 \\
LVESD & 2.67 & 2.7 & 0.457 \\
\hline
\end{tabular}

MAC: Mitral annular calcification, LVH: Left ventricular hypertrophy, LA: Left atrial, LVEDD: Left ventricular end diastolic diameter, LVESD: Left ventricular end systolic diameter

Table 2: Serum matrix gla protein levels of patients and control groups

\begin{tabular}{lccc}
\hline & Group 1 (MAC) & Group 2 (control) & $\boldsymbol{P}$ \\
\hline mGLA protein $(\mathrm{pg} / \mathrm{dl})$ & 216.1 & 390.2 & 0.001 \\
\hline MAC: Mitral annular calcification & &
\end{tabular}

important inhibitor of dystrophic valvular calcification and that this function does not require the presence of severe CAD, kidney disease, or other traditional cardiovascular risk factors. Future studies are required to evaluate whether MGP is associated with dystrophic calcification among other vascular tissues, whether the results may be generalized to individuals without coronary heart disease, and whether MGP concentrations may predict longitudinal progression of dystrophic calcification. This study adds to a growing body of literature demonstrating that serum ucMGP levels affect the regulation of cardiac valvular calcification, and this function is not different in people without significant CAD.

\section{Financial support and sponsorship}

Nil.

\section{Conflicts of interest}

There are no conflicts of interest.

\section{REFERENCES}

1. D'Cruz I, Panetta F, Cohen H, Glick G. Submitral calcification or sclerosis in elderly patients: $\mathrm{M}$ mode and two dimensional echocardiography in "mitral anulus calcification". Am J Cardiol 1979;44:31-8.

2. Hirschfeld DS, Emilson BB. Echocardiogram in calcified mitral anulus. Am J Cardiol 1975;36:354-6.

3. Fulkerson PK, Beaver BM, Auseon JC, Graber HL. Calcification of the mitral annulus: Etiology, clinical associations, complications and therapy. Am J Med 1979;66:967-77.

4. Korn D, Desanctis RW, Sell S. Massive calcification of the mitral annulus. A clinicopathological study of fourteen cases. N Engl J Med 1962;267:900-9.

5. Savage DD, Garrison RJ, Castelli WP, McNamara PM, Anderson SJ, Kannel WB, et al. Prevalence of submitral (anular) calcium and its 
correlates in a general population-based sample (the Framingham study). Am J Cardiol 1983;51:1375-8.

6. Nestico PF, Depace NL, Morganroth J, Kotler MN, Ross J. Mitral annular calcification: Clinical, pathophysiology, and echocardiographic review. Am Heart J 1984;107:989-96.

7. Benjamin EJ, Plehn JF, D’Agostino RB, Belanger AJ, Comai K, Fuller DL, et al. Mitral annular calcification and the risk of stroke in an elderly cohort. N Engl J Med 1992;327:374-9.

8. Adler Y, Herz I, Vaturi M, Fusman R, Shohat-Zabarski R, Fink N, et al. Mitral annular calcium detected by transthoracic echocardiography is a marker for high prevalence and severity of coronary artery disease in patients undergoing coronary angiography. Am J Cardiol 1998;82:1183-6.

9. Fox CS, Vasan RS, Parise H, Levy D, O’Donnell CJ, D'Agostino RB, et al. Mitral annular calcification predicts cardiovascular morbidity and mortality: The Framingham heart study. Circulation 2003;107:1492-6.

10. Price PA, Urist MR, Otawara Y. Matrix Gla protein, a new gamma-carboxyglutamic acid-containing protein which is associated with the organic matrix of bone. Biochem Biophys Res Commun 1983;117:765-71

11. Fraser JD, Price PA. Lung, heart, and kidney express high levels of mRNA for the vitamin K-dependent matrix Gla protein. Implications for the possible functions of matrix gla protein and for the tissue distribution of the gamma-carboxylase. J Biol Chem 1988;263:11033-6.

12. Luo G, Ducy P, McKee MD, Pinero GJ, Loyer E, Behringer RR, et al. Spontaneous calcification of arteries and cartilage in mice lacking matrix GLA protein. Nature 1997;386:78-81.
13. Cranenburg EC, Vermeer C, Koos R, Boumans ML, Hackeng TM, Bouwman FG, et al. The circulating inactive form of matrix Gla protein (ucMGP) as a biomarker for cardiovascular calcification. J Vasc Res 2008;45:427-36.

14. Parker BD, Schurgers LJ, Vermeer C, Schiller NB, Whooley MA, Ix JH, et al. The association of uncarboxylated matrix Gla protein with mitral annular calcification differs by diabetes status: The heart and soul study. Atherosclerosis 2010;210:320-5.

15. Schurgers LJ, Barreto DV, Barreto FC, Liabeuf S, Renard C, Magdeleyns EJ, et al. The circulating inactive form of matrix Gla protein is a surrogate marker for vascular calcification in chronic kidney disease: A preliminary report. Clin J Am Soc Nephrol 2010;5:568-75.

16. Parker BD, Ix JH, Cranenburg EC, Vermeer C, Whooley MA, Schurgers LJ, et al. Association of kidney function and uncarboxylated matrix Gla protein: Data from the heart and soul study. Nephrol Dial Transplant 2009;24:2095-101.

17. Cranenburg EC, Brandenburg VM, Vermeer C, Stenger M, Mühlenbruch G, Mahnken AH, et al. Uncarboxylated matrix Gla protein (ucMGP) is associated with coronary artery calcification in haemodialysis patients. Thromb Haemost 2009;101:359-66.

18. Shioi A, Nishizawa Y. Vascular calcification in chronic kidney disease: Pathogenesis and clinical implications. J Ren Nutr 2009;19:78-81.

19. Cassidy-Bushrow AE, Bielak LF, Levin AM, Sheedy PF $2^{\text {nd }}$, Turner ST, Boerwinkle E, et al. Matrix Gla protein gene polymorphism is associated with increased coronary artery calcification progression. Arterioscler Thromb Vasc Biol 2013;33:645-51. 